\title{
Improved biogas production from palm oil mill effluent by a scaled-down anaerobic treatment process.
}

\begin{abstract}
This is a scale-down study of a 500-m3 methane recovery test plant for anaerobic treatment of palm oil mill effluent (POME) where biomass washout has become one of the problems because of the continuous mixing of effluent during anaerobic treatment of POME. Therefore, in this study, anaerobic POME treatment using a scaled down 50-1 bioreactor which mimicked the 500-m3 bioreactor was carried out to improve biogas production with and without biomass sedimentation. Three sets of experiments were conducted under different conditions in terms of biomass sedimentation applied to the system. The first experiment was operated under semi-continuous mode whereas the second and third experiments were operated based on mix and settle mode. As expected, biomass retention improved the anaerobic process as the POME treatment incorporated with mix and settle system were able to operate at an organic loading rate (OLR) of 3.5 and $6.0 \mathrm{~kg} \mathrm{COD} / \mathrm{m} 3 /$ day respectively, while the semi continuous operated anaerobic treatment only achieved OLR of $3.0 \mathrm{~kg} \mathrm{COD} / \mathrm{m} 3 /$ day. The highest biogas and methane production rates achieved were 2.42 $\mathrm{m} 3 / \mathrm{m} 3$ of reactor/day and $0.992 \mathrm{~m} 3 / \mathrm{m} 3$ of reactor/day, respectively at OLR $6.0 \mathrm{~kg}$ $\mathrm{COD} / \mathrm{m} 3 /$ day. The biomass or solids retention in the reactors was represented by the total solids measured in this study.
\end{abstract}

Keyword: Palm oil mill effluent; Anaerobic treatment; Biogas production; Organic loading rate; Biomass sedimentation. 